\title{
Estudo botânico, fitoquímico e fisico-químico de Euphorbia hirta L. (Euphorbiaceae)
}

\author{
PINTO, M.V.1; NOGUEIRA, J.C.M. ${ }^{2}$; TRESVENZOL, L.M.F.'; FIUZA, T.S. ${ }^{1 ;}$ PAULA, J.R. ${ }^{1 ;}$ BARA, M.T.F.1* \\ 1 Universidade Federal de Goiás. Faculdade de Farmácia. Av. Universitária com $1^{1}$ Avenida s $n$, Setor Universitário \\ CEP: 74605-220. Goiânia-Brasil *mbara@farmacia.ufg.br ${ }^{2}$ Hospital de Medicina Alternativa - Secretaria Estadual \\ de Saúde do Estado de Goiás (HMA/SES-GO). Rodovia BR 153, km 8. CEP 74.000-000
}

\begin{abstract}
RESUMO: Euphorbia hirta L., popularmente conhecida por erva andorinha, tem sido utilizada no tratamento de distúrbios respiratórios e como antiespasmódico. Esse trabalho foi realizado com a finalidade de determinar as características macroscópicas e microscópicas das folhas, caule e raiz dessa planta, uma vez que estas são as partes usadas popularmente. Algumas características de valor na sua diagnose foram apontadas e ilustradas por fotomicrografias. Reações de fitoquímica e a determinação do conteúdo de água e de cinzas foram realizadas no pó obtido da planta inteira, parte essa utilizada na fitoterapia Ayuverda. Na prospecção fitoquímica foram encontrados flavonóides, mucilagem, resinas e cumarinas. Na determinação do teor de água, de cinzas totais e de cinzas insolúveis em ácido, os valores encontrados foram $8,99 \%, 9,35 \%, 0,75 \%$, respectivamente. Com o desenvolvimento deste trabalho foi possível obter parâmetros para o controle de qualidade das folhas, caule e raízes de $E$. hirta.
\end{abstract}

Palavras-chave: planta medicinal, erva-andorinha, morfoanatomia, farmacognosia, controle de qualidade

\begin{abstract}
Botanical, phytochemical and physicochemical study of Euphorbia hirta L. (Euphorbiaceae). The Euphorbia hirta L. has been used in the treatment of respiratory disorders and as an antispasmodic. This work was carried out to determine the macroscopic and microscopic characteristics of the leaves, stems and roots of this plant, as these parts are commonly used. Some features of value in their diagnosis were identified and illustrated by photomicrographs. Phytochemical reactions and determination of water and ash contents were carried out in the powder obtained from the whole plant, the part used in Ayurveda phytomedicine. In phytochemical screening, we found flavonoids, mucilage, resins and coumarins. The values of water content, total ashes and acid insoluble ashes were $8.99 \%, 9.35 \%, 0.75 \%$, respectively. The data obtained are important for the quality control of the leaves, stems and roots of $E$. hirta.
\end{abstract}

Keywords: medicinal plant, morphoanatomy, pharmacognosy, quality control

\section{INTRODUÇÃO}

A fitoterapia estuda a utilização dos produtos de origem vegetal com finalidade terapêutica (Schulz et al., 2002). Quando se refere ao uso seguro de plantas medicinais é muito importante a correta identificação botânica de uma espécie vegetal por meio de comparações macroscópicas e microscópicas com as descrições de plantas autênticas (Capasso et al., 2000; Calixto, 2000). Além disso, deve-se investigar seus constituintes químicos, pois eles podem variar em razão de fatores genéticos e ambientais, métodos de extração e secagem, o que pode afetar o controle de qualidade e o valor terapêutico de fitoterápicos
(Bara et al., 2006; Gobbo-Netto \& Lopes, 2007).

Em Goiânia-Goiás, existe o Hospital de Medicina Alternativa (HMA/SES-GO), que atende aos pacientes do SUS (Sistema Único de Saúde) por meio de terapias complementares, como a fitoterapia, em que são utilizadas aproximadamente 90 plantas medicinais, dentre estas, a Euphorbia hirta, Euphorbiaceae. Esta família compreende cerca de 300 gêneros e aproximadamente 6000 espécies. No Brasil, ocorrem cerca de 70 gêneros e 1000 espécies (Souza \& Lorenzi, 2008). Pertence às Malpighiales, a qual inclui muitas espécies venenosas e de uso medicinal de ocorrência, 
principalmente, em regiões tropicais (Judd et al., 1999).

E. hirta, também conhecida como Chamaesyce hirta (L.) Millsp, Euphorbia pilulifera L. e Euphorbia capitata Lam. (mobot, 2012), é conhecida popularmente como erva-andorinha, erva-de santa luzia, folha-de-leite ou eufórbia. $\mathrm{Na}$ composição encontram-se alcanos, triterpenos, fitosterois, taninos, polifenois e flavonoides (Liu et al., 2007; Kumar, 2010). Esta planta tem sido utilizada em caso de distúrbios respiratórios, tais como asma, bronquite, espasmo laríngeo (Corrêa, 1984; Newall et al., 2002), e no tratamento de amebíase intestinal (Newall et al., 2002). Possui atividades antibacteriana (Vijaya et al., 1995; Sudhakar et al., 2006), antifúngica (Polachini, 2004), antiretroviral (Gyuris et al, 2009) antiespasmódica (Gnecco et al.,1996 apud kumar, 2010), antianafilática (Youssouf et al., 2007), antialérgica (Singh et al., 2006), ansiolítica (Anuradha et al., 2008), antimalárica (Liu et al., 2007), anti-leucêmica (Jain et al., 2009) e anti-inflamatória contra asma (Ekpo \& Pretorius, 2007). Estudos também demonstraram que esta planta diminui a motilidade gastrintestinal (Hore et al., 2006), reduz a degeneração da cartilagem em casos de artrite (Lee et al., 2008), é antidepressiva (Lanhers et al., 1996), sedativa e ansiolítica (Lanhers et al,, 1990), e pode apresentar diarreia severa como principal efeito colateral, se utilizada em altas doses (Al-Qura'n, 2005).

Diante do exposto, o presente trabalho visou o estudo farmacognóstico da folha, caule e raiz da E. hirta, assim como do pó da planta, utilizado no HMA/SES-GO, com a finalidade de definir parâmetros para o controle de qualidade da espécie, uma vez que esses dados não foram encontrados na literatura consultada.

\section{MATERIAL E MÉTODO}

\section{Espécie utilizada}

O material botânico (folhas, caule e raiz) de E. hirta foi coletado no Hospital de Medicina Alternativa (HMA/SES-GO), localizado a $863 \mathrm{~m}$ de altitude, $16^{\circ} 43^{\prime} 50,3^{\prime \prime}$ sul e 49¹4'32,9"oeste, no dia 10 de novembro de 2006, às 9 horas da manhã.

A identificação da espécie foi realizada pelo Prof. Dr. José Realino de Paula, da FF/UFG. Uma exsicata foi depositada sob o no UFG-40.472, no Herbário da Universidade Federal de Goiás.

\section{Estudo morfoanatômico}

Descrições detalhadas dos aspectos macroscópicos da folha, caule e raiz de $E$. hirta foram realizadas conforme Oliveira \& Akisue (1997), assim como descrições detalhadas dos aspectos macroscópicos do pó da planta.

Foram realizados estudos microscópicos de cortes histológicos da folha, caule e raiz de $E$. hirta submetidos à dupla coloração azul de alcian safranina e/ou Steinmetz (Kraus et al., 1998). Primeiramente, fragmentos das diversas partes da planta (folha, pecíolo, caule e raiz principal) foram fixados em FPA 70\% (formaldeído, ácido propiônico, e etanol 70\%, 1:1:18 v/v) por 3 dias e, em seguida, conservados em etanol $70 \%$. Numa etapa posterior esse material fixado foi utilizado para a obtenção de cortes histológicos à mão livre (paradérmicos) ou com o auxílio de um micrótomo de mesa.

A microscopia do pó foi realizada após tratamento com reagente de Steinmetz (Costa, 2001).

As estruturas foram observadas em fotomicroscópio Zeiss-Axioscop ${ }^{\circledR}$, sendo a documentação registrada em filme Kodacolor ASA 100.

\section{Prospecção fitoquímica e ensaios de pureza \\ O pó (planta inteira) de E. hirta produzido e} utilizado no HMA/SES-GO foi enviado ao laboratório para as análises fitoquímicas e ensaios de pureza (umidade e cinzas), cujo lote de processamento recebeu o n॰110106-0027E.

Os metabólitos secundários presentes foram investigados segundo Costa (2001). Os teores de água e de cinzas totais e insolúveis foram realizados por gravimetria conforme a Farmacopéia Brasileira (1988).

\section{RESULTADO}

\section{Estudo morfoanatômico}

E. hirta é planta de pequeno porte (mais ou menos $50 \mathrm{~cm}$ de altura), possui raízes principais e secundárias latescentes e inflorescências pequenas que acompanham as folhas ao longo do caule (Figuras 1A e 1B).

As folhas são inteiras, flexíveis, de ápice agudo, base cuneada, contorno oval, margem serreada, nervação peninérvea. A superfície do limbo é áspera e pubescente. O pecíolo é piloso, latescente, reto, de inserção lateral e secção transversal circular. Possuem tamanho que varia, aproximadamente, de $4 \times 2 \mathrm{~cm}$ a $3,5 \times 1,5 \mathrm{~cm}$ (comprimento x largura), de coloração verde-escuro na epiderme da face adaxial e verde claro na epiderme da face abaxial. São inodoras.

FIGURA 1. E. hirta - aspecto geral e detalhe da parte aérea 

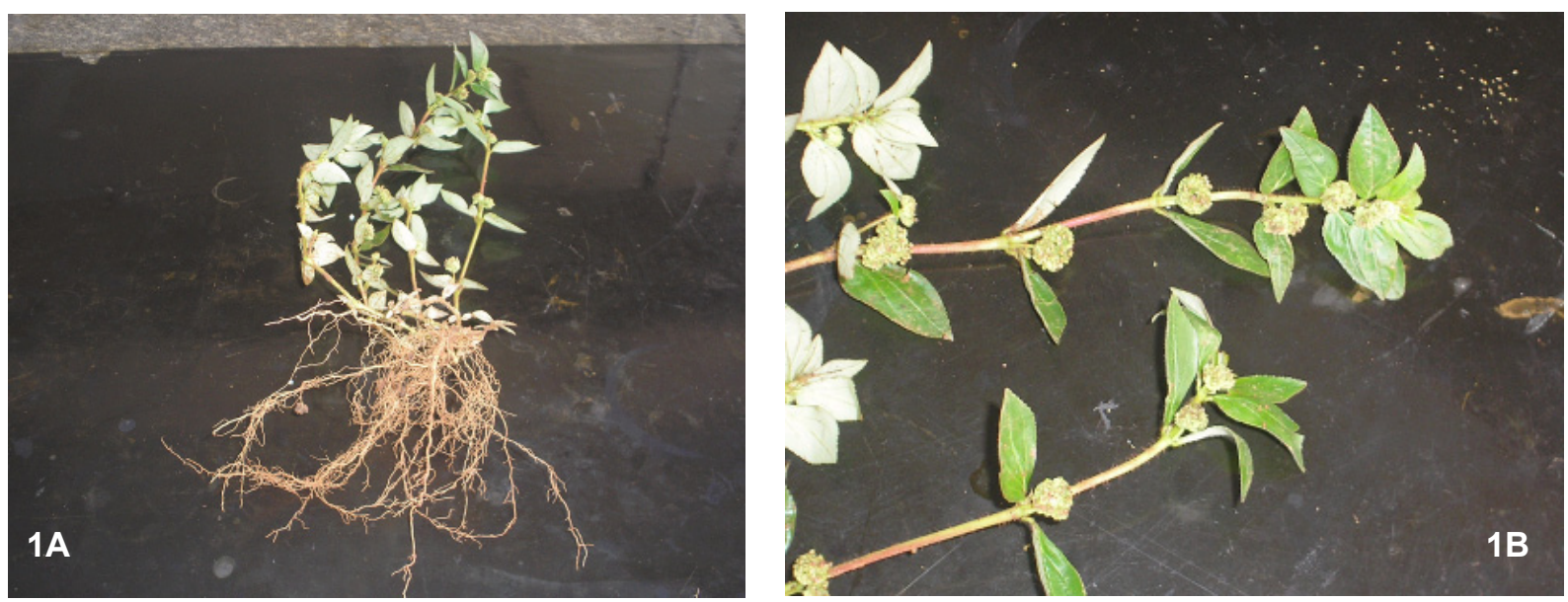

FIGURA 1. E. hirta - aspecto geral e detalhe da parte aérea

Em relação às características macroscópicas do pó de E. hirta, esse é de textura fina, cor verde claro a amarelado.

Em secção paradérmica das folhas de $E$. hirta observou-se que a mesma é anfiestomática (Figuras 2Ae 2B) com estômatos predominantemente anisocíticos. As células da epiderme da face abaxial apresentam paredes anticlinais ondeadas (Figura 2B) e as da epiderme da face adaxial apresentam paredes anticlinais predominantemente retas (Figura 2A).

Em ambas as faces da epiderme das folhas de E. hirta foi observada a presença de tricomas pluricelulares unisseriados (Figuras 2C e 2D).
2A
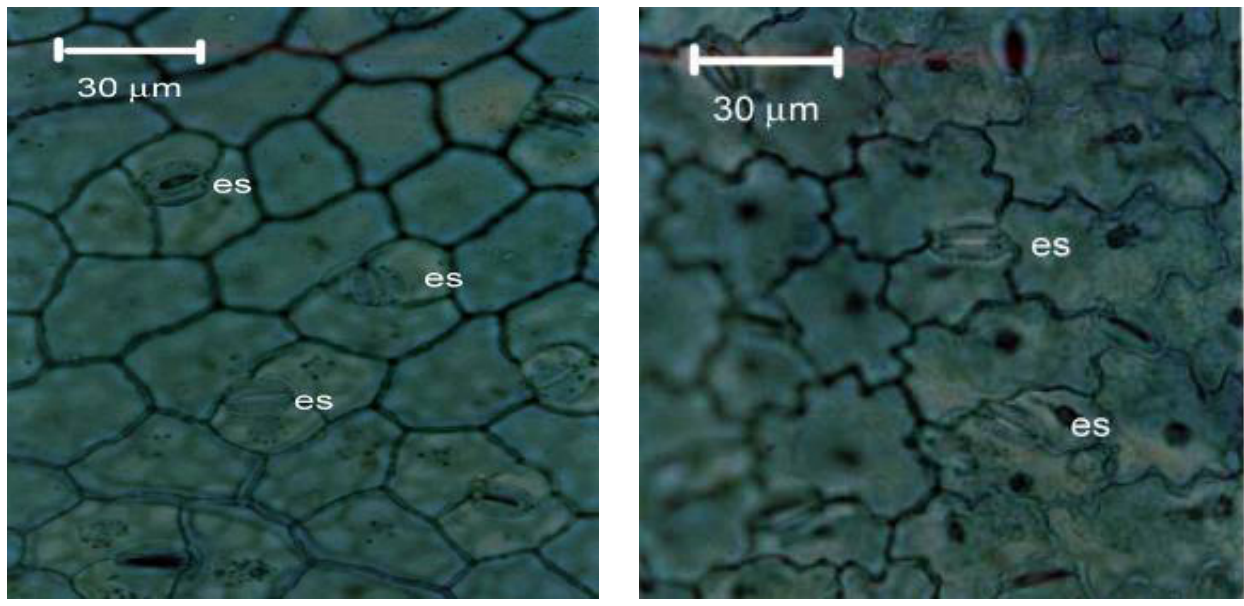

2B

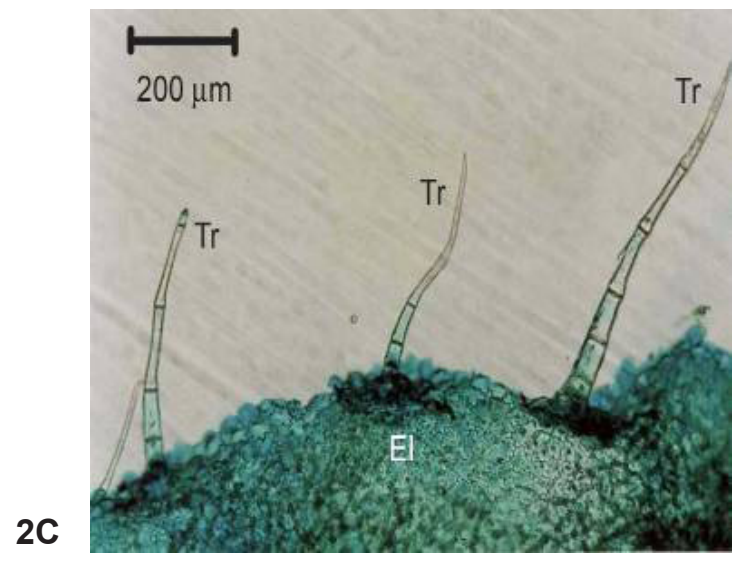

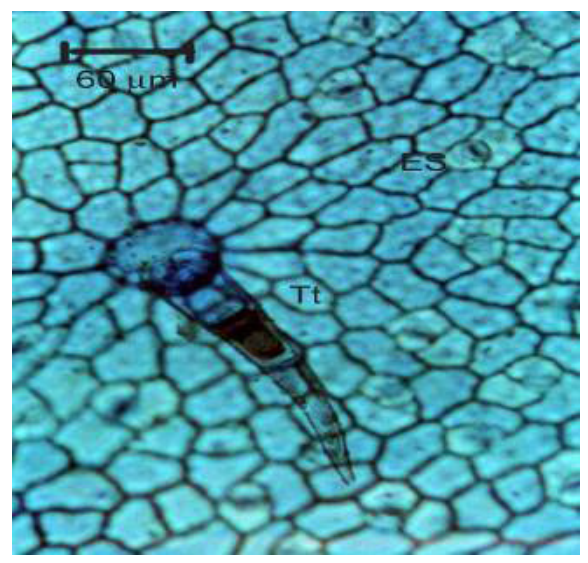

2D

FIGURA 2. Análise microscópica das folhas de E. hirta em corte paradérmico submetido à coloração de azul de alcian safranina. es- estômato; ES- epiderme da face adaxial; Tt- tricoma tector; Tr- tricoma; EI- epiderme da face inferior. 
Em secção transversal da região da internervura da folha de E. hirta o mesofilo é dorsiventral, apresentando parênquima paliçádico bisseriado ocupando cerca da metade do mesofilo
(Figuras 3A e 3B). O parênquima lacunoso ocupa cerca da metade do mesofilo e ambas as faces da epiderme são unisseriadas, contendo a face abaxial células papilosas (Figuras 3A e 3B).
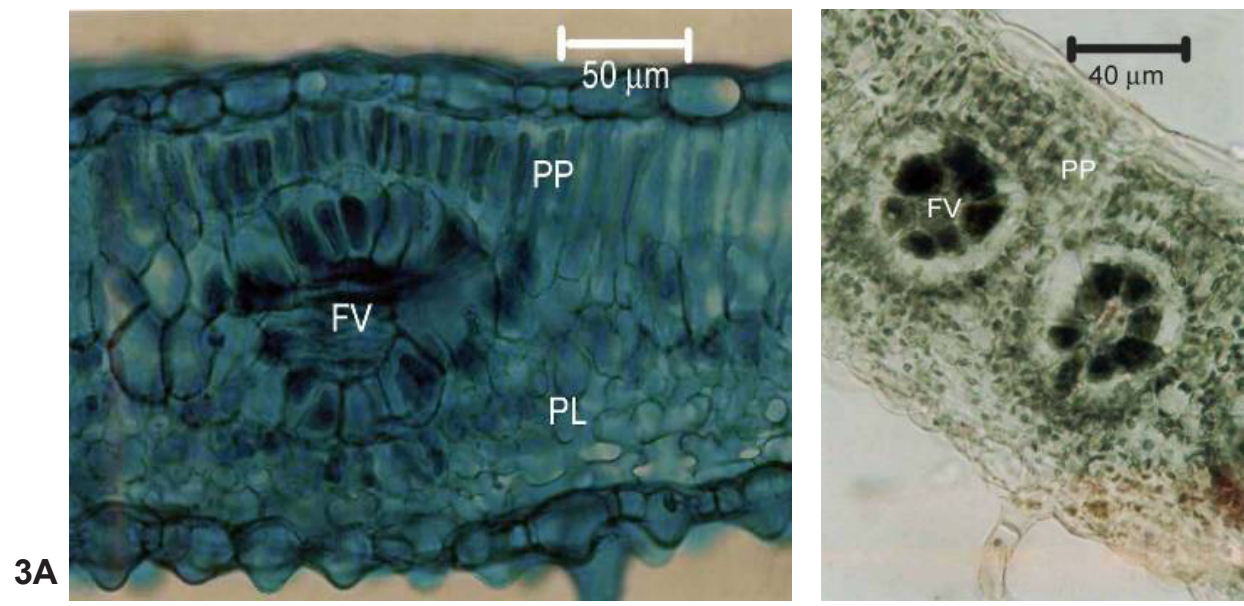

3B

FIGURA 3. Análise microscópica das folhas de E. hirta na região da internervura em secção transversal submetido à coloração de azul de alcian safranina (A) e Steinmetz (B). FV- feixe vascular; PL- parênquima lacunoso; PPparênquima paliçádico.

4A
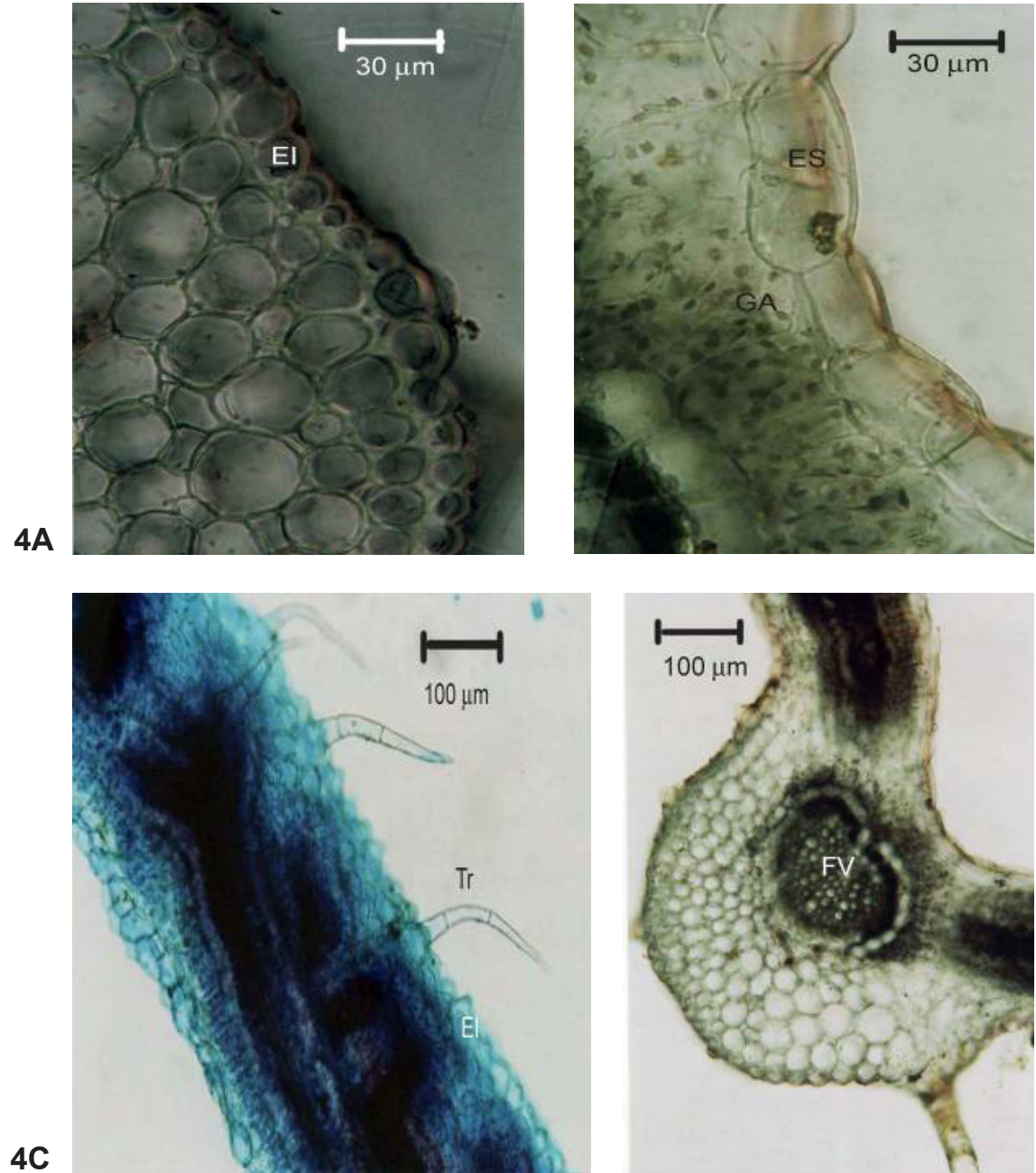

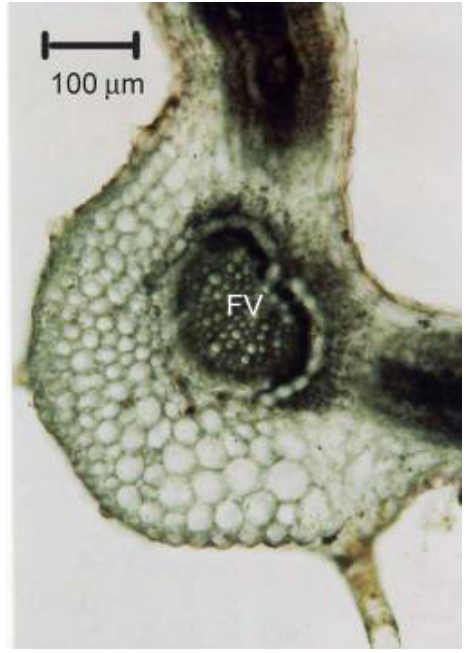

4B

FIGURA 4. Análise microscópica das folhas de E. hirta na região da nervura principal em secção transversal submetido à coloração de Steinmetz (A,B e D) e azul de alcian safranina (C). El- epiderme abaxial; ES- epiderme adaxial; GA- grãos de amido; FVfeixe vascular;Tr-tricoma tector. 
No corte transversal da folha de E. hirta na região da nervura principal observou-se epiderme unisseriada com cutícula espessa (Figuras 4A e 4B), tricomas tectores na epiderme abaxial (Figura 4C), feixe vascular central (Figura 4D) e colênquima angular com três camadas de células (Figura 4A). Observou-se a presença de grãos de amido próximo ao feixe vascular central (Figura 4B) e foram detectados compostos fenólicos no parênquima paliçádico (Figura 4D, região escura), quando o corte foi tratado com a coloração diferencial de Steinmetz, que contem sais de ferro (Costa, 2001).

A secção transversal da região mediana do pecíolo apresentou tricomas pluricelulares, unisseriados, epiderme unisseriada e sistema vascular central com feixes dispostos em arco voltado para epiderme da face adaxial (Figura 5).

O caule em estrutura secundária apresenta epiderme unisseriada com cutícula espessa em flanges e tricomas tectores pluricelulares unisseriados, colênquima com até três camadas

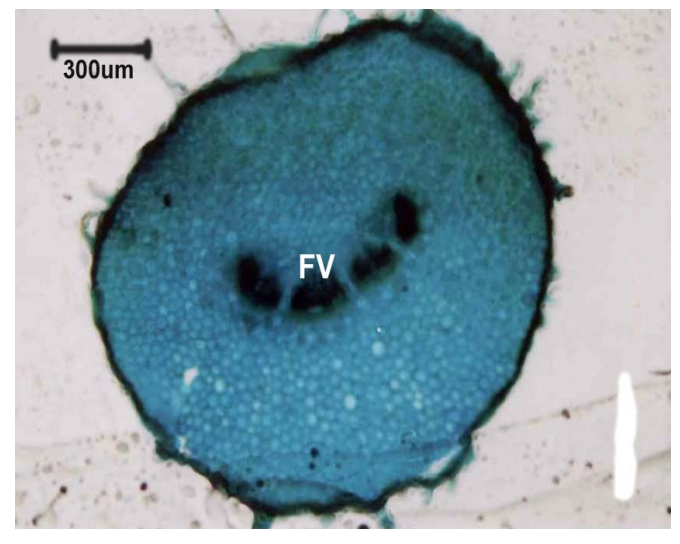

FIGURA 5. Corte transversal do pecíolo de E. hirta submetida à coloração azul de alcian safranina. FV- feixe vascular. de células, parênquima cortical. O sistema vascular do caule apresenta floema externo ao xilema envolvendo um parênquima medular e é possível observar a descontinuidade do xilema em alguns pontos (Figuras 6A e 6B).

A raiz, em estrutura secundária, apresenta súber, parênquima cortical e floema externo ao xilema no cilindro central. Observou-se xilema com vasos de grande calibre isolados ou em grupos de dois até quatro vasos (Figura $6 \mathrm{C}$ ).

$\mathrm{Na}$ microscopia do pó detectou-se a presença de grãos de amido esféricos, isolados e em grupos de três, e grãos de pólen (Figura 7). Detectou-se também a presença de fragmentos de epiderme adaxial e de tricomas tectores pluricelulares, unisseriados, fragmentos de vasos e fragmentos contendo fibras esclerenquimáticas (Figura 8).

\section{Prospecção fitoquímica e ensaios de pureza}

No estudo fitoquímico qualitativo avaliou-se as principais classes de metabólitos secundários presentes no pó de E. hirta (HMA-SES/GO) e detectou-se a presença de flavonóides, cumarinas, mucilagem e resinas (Quadro1).

O teor de umidade obtido foi $8,9923 \pm 0,0512$ $\%$, os teores de cinzas totais e cinzas insolúveis em ácido clorídrico, encontrados para $E$. hirta cultivada no HMA/SES-GO, foram respectivamente 9,3467 \pm $0,1754 \%$ e $0,7490 \pm 0,0646 \%$.

\section{DISCUSSÃO}

As características macroscópicas observadas para $E$. hirta estão de acordo com as apontadas por Judd et al. (1999) para as Euphorbiaceae, que é constituída de árvores, arbustos, ervas ou videiras algumas vezes suculentas e semelhantes a cactos, quimicamente

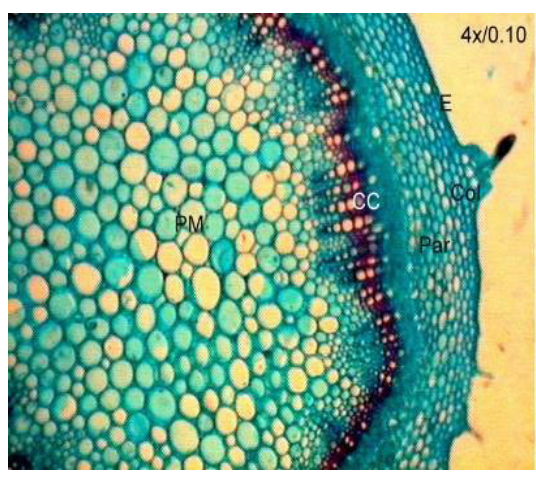

$6 \mathrm{~A}$

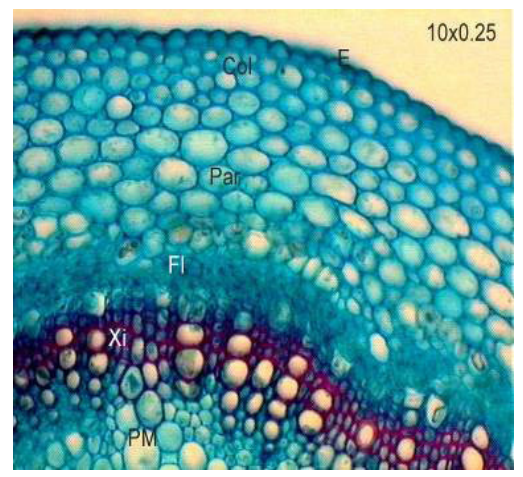

6B

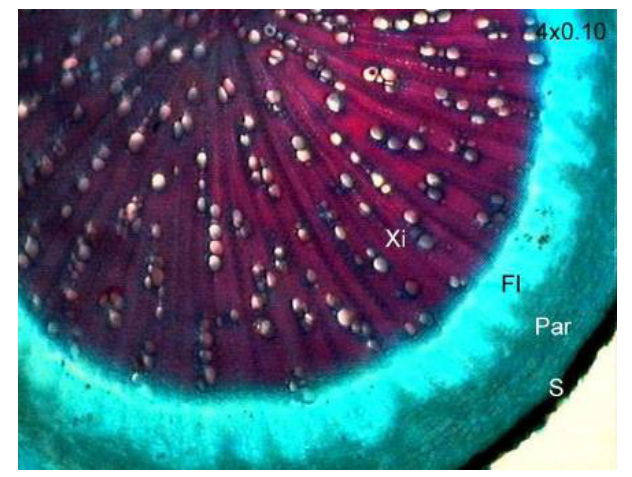

$6 \mathrm{C}$

FIGURA 6. Corte transversal do caule (A e B) e da raiz (C) de E. hirta submetidos à coloração azul de alcian safranina. E- epiderme; Col- colênquima; Par- parênquima cortical; CC- cilindro central; PM- parênquima medular; Fl- floema; Xi- xilema; S-súber.

Rev. Bras. PI. Med., Campinas, v.16, n.3, supl. I, p.649-656, 2014. 


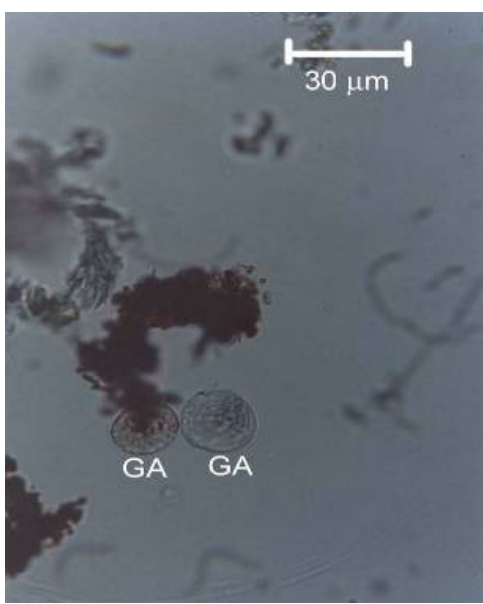

7A

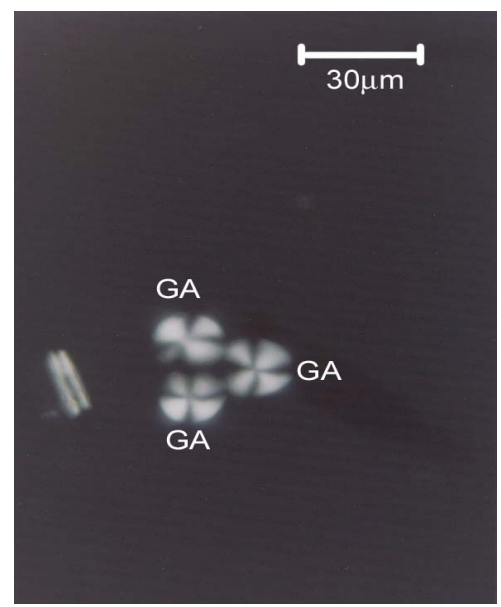

7B

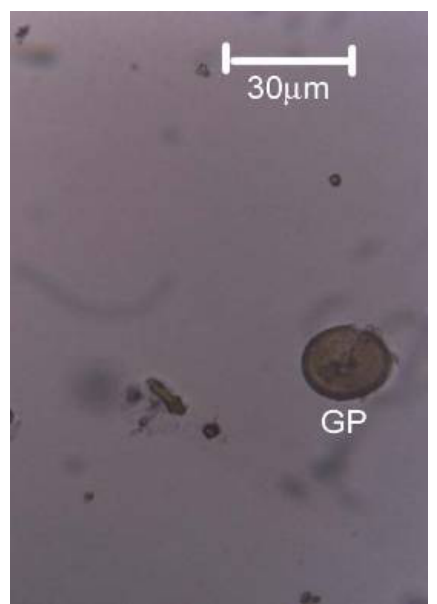

7C

FIGURA 7. Microscopia de pó de E. hirta. A- Grãos de amido isolados. B- Grãos de amido agrupados em grupos de três em luz polarizada. C- Grão de pólen. GA- grão de amido; GP- grão de pólen.

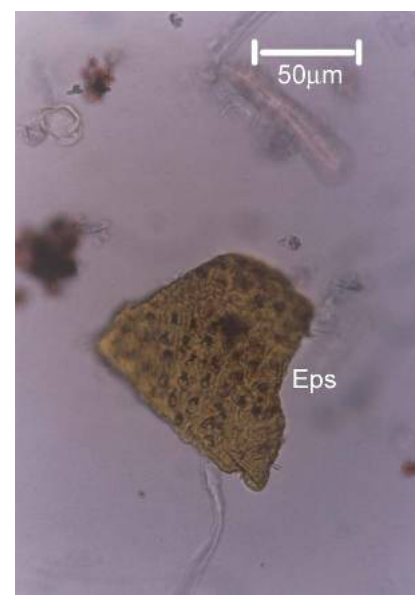

8A

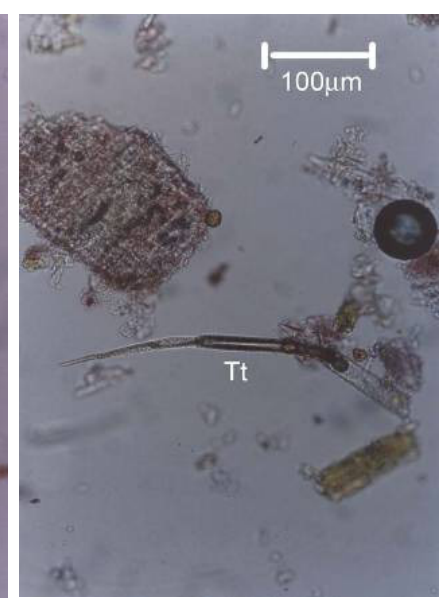

8B

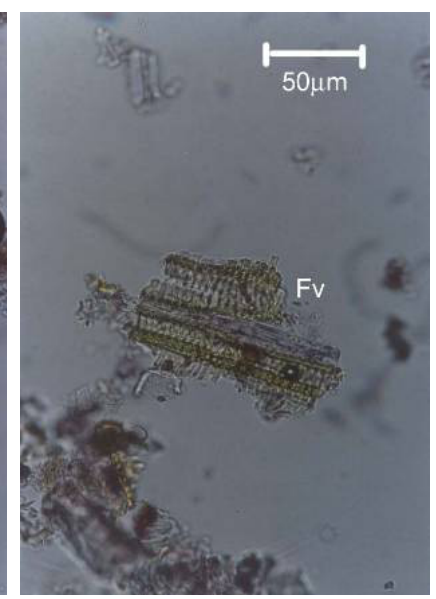

$8 \mathrm{C}$

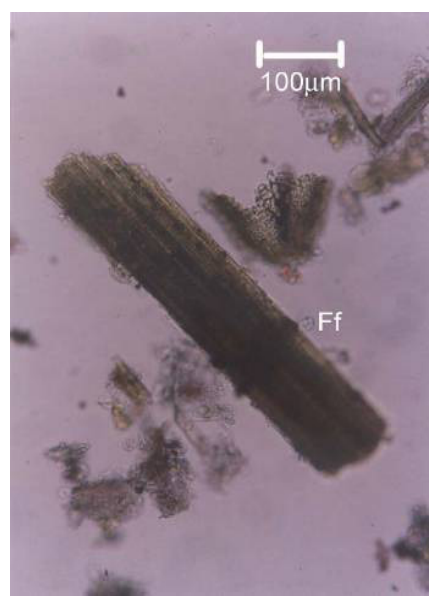

8D

FIGURA 8. Microscopia de pó de E. hirta. A- Fragmento de epiderme superior. B-Tricoma tector pluricelular unisseriado. C- Fragmento de vasos. D- Fragmento contendo fibras. Eps- Epiderme superior. Tt- tricoma tector. Fv- fragmentos de vasos com espessamento em anel. Ff- fragmento de fibras.

QUADRO 1. Prospecção fitoquímica de E. hirta (pó da planta inteira).

\begin{tabular}{lc}
\hline Ensaio & Resultado \\
\hline Pesquisa de Antraquinonas & Negativo \\
Pesquisa de Digitálicos & Negativo \\
Pesquisa de Flavonoides & Positivo \\
Pesquisa de Saponinas & Negativo \\
Pesquisa de Taninos & Negativo \\
Pesquisa de Alcaloides & Negativo \\
Pesquisa de Mucilagem & Positivo \\
Pesquisa de Cumarinas & Positivo \\
Pesquisa de Resinas & Positivo \\
\hline
\end{tabular}

diversas, com alcalóides, di ou triterpenoides, taninos, látex leitoso, geralmente venenoso. As folhas são geralmente alternadas, simples, às vezes compostas palmadas, serreadas, com nervação palminérvea e estípulas geralmente estão presentes. Apresentam inflorescências geralmente modificadas formando falsas flores terminais ou axiais. Alguns membros da família também apresentam látex, tricomas, folhas alternas e pilosas, podendo ser estas características morfológicas comuns dentro da família (Randau et al., 2004). Segundo Corrêa (1984), a planta é crespo-pubescente, com caules eretos, folhas ovado-lanceoladas, agudas, serrilhadas ou denteadas.

Não foram encontrados dados na literatura pesquisada acerca do controle de qualidade 
microscópico dessa planta.

Alguns constituintes ativos da $E$. hirta têm sido detectados, destacando-se a presença de flavonoides tais como a quercetina (Hallet \& Parks, 1951; Liu et al., 2007), leucocianidina e xantoramnina (Newall et al., 2002), afazelina e miricitrina (Liu et al., 2007), o que condiz com o resultado encontrado na prospecção fitoquímica realizada neste trabalho. Estudo de Bhagwat et al. (2008) revelou a presença de esteroides, alcaloides, carboidratos, proteínas e compostos fenólicos (flavonoides, taninos e saponinas). A presença dessas substâncias pode justificar o uso da espécie como medicinal.

A determinação do teor de umidade teve como objetivo caracterizar a amostra analisada visando sua conservação. $O$ excesso de umidade permite a ação de enzimas, podendo acarretar a degradação dos constituintes químicos, além de possibilitar o desenvolvimento de fungos e bactérias (Farias, 2004). Segundo a Farmacopéia Brasileira 4a Edição (1988), deve estar compreendida na faixa de 8 a $14 \%$.

A determinação do teor de cinzas totais foi feita com o intuito de se conhecer valores de cinzas fisiológicas para essa planta medicinal (parte usada: planta inteira). Essa informação pode detectar ou prevenir a adulteração ou contaminação por impurezas inorgânicas não voláteis que podem estar presentes. A determinação do teor de cinzas insolúveis em ácido visa à detecção de sílica e componentes silicosos (Farias, 2004).

Com o desenvolvimento deste trabalho pôde-se obter parâmetros que podem ser utilizados para o controle de qualidade das folhas, caule e raízes de $E$. hirta (erva-andorinha). Com isso, cumpre-se a primeira etapa no controle de qualidade dessa matéria-prima vegetal.

\section{AGRADECIMENTO}

À Secretaria de Ciência e Tecnologia do Estado de Goiás (SECTEC-GO) e ao CNPq (Edital PPP-SUS, 2004), pelo aporte financeiro.

\section{REFERÊNCIA}

AL-QURA'N, S. Ethnobotanical survey of folk toxic plants in southern part of Jordan. Toxicon, v.46, p.119-129, 2005.

ANURADHA, H.et al. Euphorbia hirta reverses chronic stress-induced anxiety and mediates its action through the $\mathrm{GABA}_{\mathrm{A}}$ receptor benzodiazepine receptor-Cl-channel complex. Journal of Neural Transmission, v.115, p.35-42, 2008.

BARA, M.T.F.et al. Determinação do teor de princípio ativo em matérias-primas vegetais. Revista Brasileira de Farmacognosia, v.16, n.2, p.211-5, 2006.

BHAGWAT, G.G.et al. Pharmacognostic Study of Plant
Euphorbia hirta L. Journal of Pharmacy Research, v.1, n.1, p.39-43, 2008.

CAPASSO, R. et al. Phytotherapy and quality of herbal medicines. Fitoterapia, v.71, p.S58-S65, 2000.

CALIXTO, J.B. Efficacy, safety, quality control, marketing and regulatory guidelines for herbal medicines (phytotherapeutic agents). Brazilian Journal of Medical and Biological Research, v. 33, p.179-89, 2000.

CORREA, M.P. Dicionário das Plantas Úteis do Brasil. Rio de Janeiro: Instituto Brasileiro de Desenvolvimento Florestal, 1984. 707p.

COSTA, A.F. Farmacognosia. $3^{a}$ edição. Lisboa: Fundação Calouste Gulbenkian, v.3, 2001. 992p.

EKPO,O.E.; PRETORIUS, E. Asthma, Euphorbia hirta and its anti-inflammatory properties. South African Journal of Science, v.103, p.201-3, 2007.

FARIAS, M.R. Avaliação da Qualidade de Matérias-Primas Vegetais. In: SIMÕ̃ES, C.M.O. et al. Farmacognosia: da planta ao medicamento. 5.ed. Porto Alegre: Editora da UFRGS, 2004. p.263-88.

FARMACOPÉIA BRASILEIRA. 4.ed. São Paulo: Atheneu, 1988. parte 1. 158p.

GYURIS, A. et al. Antiviral activities of extracts of Euphorbia hirta L. against HIV-1, HIV-2 and SIVmac251. In Vivo, v.23, n.3, p.429-32, 2009.

GOBBO-NETTO, L.; LOPES, N.P. Plantas medicinais: fatores de influência no conteúdo de metabólitos secundários. Química Nova, v.30, n.2, p.374-81, 2007.

HALLETT, F.P.; PARKS, L.M. A note on the isolation of quercitrin from Euphorbia pilulifera L. Journal of the American Pharmacists Association, v.40, n.1, p.567, 1951.

HORE, S.K. et al. Effect of aqueous Euphorbia hirta leaf extract on gastrointestinal motility. Fitoterapia, v.77, p.35-8, 2006.

JAIN, S.et al. Ayurvedic medicines in treatment of cancer. Journal of Chinese Integrative Medicine, v.7, n.11, p.1096-99, 2009.

JUDD, W.S., CAMPBELL, C.S.; KELLOGG, E.A.; STEVENS, P.F. Plant Systematics: A Phylogenetic Approach., Massachussets U.S.A.: Sinauer Associates Inc. Publishers, 1999. 464p.

KRAUS, J.E. et al. Astra blue and basic fuchsine double staining methods for plant materials. Biotechnic and Histochemistry, v.5, n.73, p.235-43, 1998.

KUMAR, S., MALHOTRA, R., KUMAR, D. Euphorbia hirta: Its chemistry, traditional and medicinal uses, and pharmacological. Pharmacognosy Review, v.4, n. 7,p. 58-61, 2010.

LANHERS, M-C.,et al. Behavioral effects of Euphorbia hirta: sedative and anxiolytic properties. Journal of Ethnopharmacology, v. 29, n. 2, p. 189-98, 1990.

LANHERS, M-C et al Neurophysiological effects of Euphorbia hirta L. (Euphorbiaceae). Phytotherapy Research, v.10, n 8, p. 670-76,1996.

LEE, K.H. et al. The effect of water extracts of Euphorbia hirta on cartilage degeneration in arthritic rats. Malaysian Journal of Pathology, v.30, n.2, p.95-102, 2008.

LIU,Y.et al. Antimalarial flavonol glycosides from Euphorbia hirta. Pharmaceutical Biology, v.45, n.4, p.278-281, 2007. 
MOBOT, Missouri Botanical Garden. Disponível em: www. tropicos.org/, acesso em aug/2012.

NEWALL, C.A.; ANDERSON, L.A.; PHILLIPSON, J.D. Plantas Medicinais, Guia para profissional de saúde. Ribeirão Preto: Editorial Premier, 2002. 123p.

OLIVEIRA, F.; AKISUE, G. Fundamentos de Farmacobotânica. 2.ed. São Paulo: Editora Atheneu, 1997. 188p.

POLACHINI, C.O. Avaliação in vitro de extratos de plantas e produtos diversos, frente a amostras de Candida albicans. 2004. 89p. Dissertação (Mestrado - Área de Concentração em Ciências) - Coordenadoria de Controle de Doenças da Secretaria Estadual de São Paulo, São Paulo.

RANDAU, K.P. et al. Estudo farmacognóstico de Croton rhamnifolius H.B.K. e Croton rhamnifolioides Pax \& Hoffm. (Euphorbiaceae). Revista Brasileira de Farmacognosia, v.14, n.2, p.89-96, 2004.

SCHULZ, V.; HANSEL, R.; TYLER, V.E. Fitoterapia Racional. São Paulo: Editora Manole Ltda, 2002. $386 \mathrm{p}$.

SHI, Q.W., SU, X.H., KIYOTA. H.Chemical and pharmacological research of the plants in genus
Euphorbia. Chemical Reviews. v.108, n.10, p.4295327, 2008.

SINGH, G.D. et al. Inhibition of early and late phase allergic reactions by Euphorbia hirta L. Phytotherapy Research, v.20, p.316-21, 2006.

SOLEREDER, H. Systematic Anatomy of the Dicotyledons: A Handbook for Laboratories of Pure and Applied Botany. Oxford: Clarendon Press, 1908. 1182p.

SOUZA, V.C., LORENZI, H. Botânica Sistemática: guia ilustrativo para identificação das famílias de fanerógamas nativas e exóticas no Brasil, baseado em APG II. Nova Odessa: Instituto Plantarum, 2008. $704 p$.

SUDHAKAR, M. et al. Antimicrobial activity of Caesalpinia pulcherrima, Euphorbia hirta and Asystasia gangeticum. Fitoterapia, v.77, p.378-80, 2006.

VIJAYA, K. et al. Antibacterial effect of theaflavin, polyphenon 60 (Camellia sinensis) and Euphorbia hirta on Shigella spp - a cell culture study. Journal of Ethnopharmacology, v.49, p. 115-8, 1995.

YOUSSOUF, M.S. et al. Anti-anaphylactic effect of Euphorbia hirta. Fitoterapia, v.78, p.535-9, 2007. 